\title{
Varón marroquí con espondilodiscitis de larga evolución, orquitis y endocarditis
}

\section{Moroccan man with longstanding spondylodiscitis, orchitis and endocarditis}

\author{
María José Munoz-Dávila, Antonio Marín, María Ángeles Muñoz, \\ TomÁs Rodríguez • MuRCIa (España)
}

\section{Resumen}

La afectación osteoarticular es la complicación más frecuente de la brucelosis. La espondilodiscitis es una complicación grave, ya que suele estar asociada con la formación de abscesos. Se presenta el caso de un varón de 43 años de edad, natural de Marruecos, con síntomas, signos y hallazgos imagenológicos de espondilodiscitis de larga evolución, orquitis y endocarditis. Mediante la realización de pruebas de laboratorio complementarias se llega al diagnóstico de infección por Brucella spp. El presente caso busca concientizar a la comunidad médica sobre la importancia de considerar la infección por Brucella spp. como diagnóstico diferencial en pacientes con sospecha de espondilodiscitis infecciosa, especialmente en aquellos pacientes con antecedentes epidemiológicos, permitiendo así realizar un acertado y oportuno diagnóstico. Este caso resulta interesante porque nunca antes se había descrito la presencia simultánea de estas tres manifestaciones de la brucelosis en un paciente inmunocompetente. (Acta Med Colomb 2015; 40: 166-168).

Palabras clave: espondilodiscitis, orquitis, endocarditis, Brucella spp, rosa de bengala y seroaglutinación de Wright.

\begin{abstract}
Osteoarticular involvement is the most common complication of brucellosis. Spondylodiscitis is a serious complication as it is often associated with abscess formation. The case of a 43 years old man born in Morocco with symptoms, signs and imaging findings of longstanding spondylodiscitis, orchitis and endocarditis is presented. Through the implementation of complementary laboratory tests, diagnosis infection by Brucella spp. was made.This case aims to raise awareness in the medical community about the importance of considering Brucella spp. as a differential diagnosis in patients with suspected infectious spondylodiscitis, especially in those patients with epidemiological background, allowing make a successful and timely diagnosis. This case is interesting because never before had been described the simultaneous presence of these three manifestations of brucellosis in an immunocompetent patient. (Acta Med Colomb 2015; 40: 166-168).

Keywords: Spondylodiscitis, orchitis, endocarditis, Brucella spp, Wright rose bengal agglutination.
\end{abstract}

\footnotetext{
Dres. María José Munoz-Dávila y Antonio Marín: Laboratorio de Microbiología, Hospital Universitario Reina Sofía; Dra. María Ángeles Muñoz: Unidad de Enfermedades Infecciosas, Hospital Universitario Reina Sofía; Dr. Tomás Rodríguez: Servicio de Microbiología, Hospital Universitario Virgen de la Arrixaca. El Palmar. Murcia (España).

Correspondencia. Dra. María José MunozDávila. Murcia (España).

E-mail: mariajose.munoz5@um.es

Recibido: 7/VI/2014 Aceptado: 21/V/2015
}

\section{Introducción}

La espondilodiscitis lumbar es una infección del disco intervertebral que afecta al cuerpo vertebral y que puede extenderse a áreas contiguas. La espondilodiscitis representa el 2-4\% del total de casos de osteomielitis (1) y tiende a afectar principalmente a la población adulta (2). Estudios realizados en nuestro país (España), han demostrado una incidencia de 0.7-2.4 casos por 100000 habitantes, con una tendencia a la desaparición de las espondilodiscitis producidas por Brucella y a la estabilización de las piógenas y tuberculosas (3).

A pesar de la tendencia a la disminución, aquí presentamos un caso de espondilodiscitis de larga evolución causada por Brucella spp en un paciente marroquí con orquitis y endocarditis como complicaciones simultáneas. Nunca antes había sido descrito en la literatura 
la presencia de estas tres manifestaciones de forma simultánea.

\section{Presentación del caso}

Varón de 43 años de edad, natural de Marruecos, residente en España desde hace 15 años, con viajes frecuentes a su país de origen, durante los que reside en ambiente rural en contacto con todo tipo de animales, al residir allí en una granja con caballos, ovejas y vacas, sin otros antecedentes clínicos de interés. En agosto de 2007 acudió a urgencias refiriendo dolor en miembro inferior izquierdo (MII) de dos meses de evolución, con diagnóstico de ciatalgia, se programó tratamiento analgésico. En septiembre de 2011 acudió a consultas externas de traumatología por presentar lumbociatalgia izquierda crónica. Refería haber sido intervenido en dos ocasiones a finales de 2007 por hernia discal lumbar. En la RMN se apreció fibrosis peridural perirradicular izquierda L4-L5 y fibrosis también en L2-L3. En este momento la lumbociatalgia se asocia a secuelas de la cirugía discal y se programa tratamiento analgésico habitual. En abril de 2012 acude a urgencias por presentar dolor a nivel lumbar con irradiación a MII desde hace una semana. Tras diagnóstico de lumbociatalgia izquierda, se continuó con tratamiento analgésico. Finalmente en octubre de 2013 es ingresado por dolor lumbar de un mes de evolución, irradiado a MII que no le permitía estar sentado, de características radiculares L4 izquierdo y que no cedía al tratamiento habitual con analgésicos. En la última semana el paciente inicia además dolor e inflamación testicular. En RMN lumbar se observó fibrosis epidural y alteración de la intensidad de señal de la médula ósea a nivel de L3, L4 y L5 (Figura 1), por lo que se recomienda descartar clínicamente una espondilitis infecciosa, ya que la gammagrafía ósea con leucocitos marcados también resultó compatible con proceso infeccioso activo en cuerpos vertebrales L2-L3.

En la ecografía testicular, el testículo derecho no mostró alteraciones mientras que en el izquierdo se observó aumento de la vascularización y presencia de dos lesiones hipoecogénicas, con flujo doppler periférico y central, sugestivo de abscesos intraparenquimatosos. El epidídimo izquierdo estaba aumentado de tamaño y de flujo doppler, con presencia de imágenes ecogénicas puntiformes con sombra en cola de cometa sugestivas de gas. El hidrocele izquierdo de pequeño tamaño presentaba algún tabique, probable piocele. Ante la sospecha de espondilitis infecciosa y la ausencia de otros focos de infección, contiguos o distantes, se realizó ecocardiografía por sospecha de espondilitis por Brucella spp, en la cual la válvula aórtica presenta una imagen nodular de unos $4 \mathrm{~mm}$ de longitud adherida a la cara ventricular del velo coronario derecho con movimiento independiente vibratorio muy sugestiva de vegetación, sin presentar afectación de la función valvular.

Previa realización de una biopsia vertebral se solicitó serología de Brucella. La prueba rosa de bengala resultó

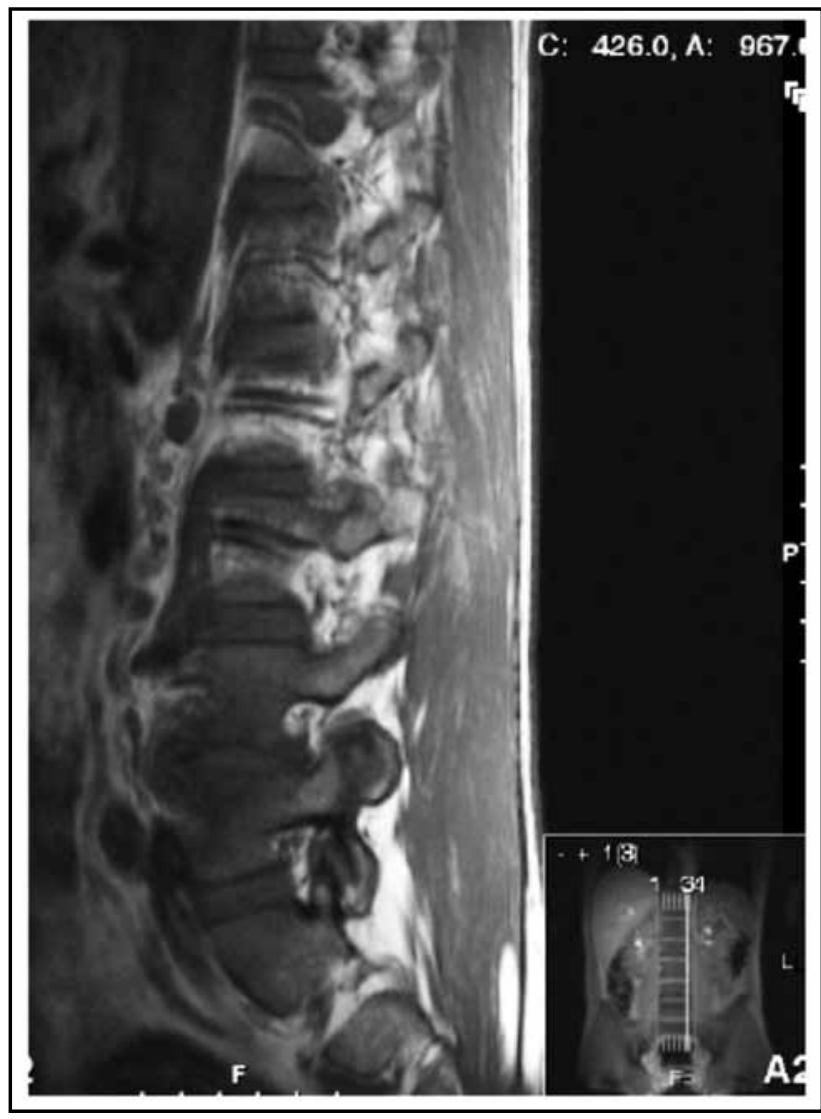

Figura 1. RM de columna lumbar en la que se observa alteración de la intensidad de señal de la médula ósea a nivel de L3, L4 y L5.

positiva. No se solicitó cultivo de semen u orina. El test de inmunocaptura de Brucella (Brucellacapt ${ }^{\circledR}$ ) y la seroaglutinación de Wright fueron positivos a la dilución 1/5120. Los hemocultivos fueron positivos para Brucella melitensis. Se inició tratamiento con doxiciclina $100 \mathrm{mg}$ [1 comp/12 horas] + rifampicina $600 \mathrm{mg}$ [ $1 \mathrm{comp} / 24$ horas], asociando posteriormente gentamicina $160 \mathrm{mg}$ [ 1 ampolla/12 horas] ante la afectación testicular y cardiaca. Durante su estancia en planta el paciente presentó una evolución favorable, con deambulación progresiva, desapareciendo la focalidad neurológica y mejorando la inflamación testicular. Tras tres semanas de tratamiento se suspende gentamicina y se decide alta para continuar seguimiento y tratamiento antibiótico (doxiciclina + rifampicina + cotrimoxazol (800/160 mg [1 comp/12 horas]) de forma ambulatoria. En la primera revisión a los dos meses del alta hospitalaria, se observa una buena evolución clínica. Se solicitó ecografía testicular que resultó normal mientras que en la resonancia magnética de columna lumbar se observa mejoría de la espondilodiscitis desde L3 a L5. El tratamiento programado al alta se mantiene hasta completar seis meses.

\section{Discusión}

La brucelosis es una zoonosis de distribución mundial causada por Brucella spp, bacteria Gram-negativa, intra- 
celular facultativa. La transmisión al ser humano se debe principalmente a la ingesta de leche o productos derivados contaminados o mediante un contacto estrecho con ganado infectado o sus secreciones o tejidos (4). La enfermedad raramente fatal, puede presentar una fase aguda febril, subaguda o crónica. El microorganismo es capaz de infectar diferentes órganos y tejidos, y en consecuencia, existe una gran variedad en las manifestaciones clínicas de la enfermedad (5). La afectación osteoarticular es la complicación más frecuente de la brucelosis y la espondilodiscitis es una complicación grave, ya que suele estar asociada con la formación de abscesos (6-8). La endocarditis es una complicación poco frecuente en los casos de brucelosis, con una prevalencia de 0.3-0.6\%. Sin embargo, es la causa de mortalidad más frecuente (9). La afectación genitourinaria (epididimitis, orquitis, prostatitis) en la brucelosis tiene una prevalencia de 2-20\% (10).

\section{Conclusión}

Con este caso clínico queremos subrayar la importancia de continuar contemplando la brucelosis en el diagnóstico diferencial de la espondilodiscitis, especialmente en aquellos pacientes con antecedentes epidemiológicos que sean sugerentes de infección por Brucella spp. Este caso resulta interesante porque nunca antes se había descrito la presencia simultánea de estas tres manifestaciones de la brucelosis en un paciente inmunocompetente.

\section{Conflicto de intereses}

Los autores expresan que no hay conflictos de intereses al redactar el manuscrito. Ninguno de los autores declara tener conflicto de intereses.

El trabajo no ha recibido ningún tipo de financiación.

\section{Referencias}

1. Khan IA, Vaccaro AR, Zlotolow DA. Management of vertebral diskitis and osteomyelitis. Orthopedics. 1999; 22(8): 758-65.

2. Pintado-García, V. Espondilitis infecciosa. Enferm Infecc Microbiol Clin 2008; 26(8): 510-7.

3. Solís-García del Pozo J, Vives-Soto M, Lizán-García M, Martínez-Alfaro E, Segura-Luque JC, Solera-Santos J. Incidence of infectious spondylitis in the province of Albacete (Spain). Enferm Infecc Microbiol Clin. 2005; 23(9): 545-50.

4. Young EJ. An overview of human brucellosis. Clin Infect Dis. 1995; 21(2): 283-9.

5. Ko J, Splitter GA. Molecular host-pathogen interaction in brucellosis: current understanding and future approaches to vaccine development for mice and humans. Clin Microbiol Rev. 2003; 16(1): 65-78.

6. Kaptan F, Gulduren HM, Sarsilmaz A, Sucu HK, Ural S, Vardar I, et al Brucellar spondylodiscitis: comparison of patients with and without abscesses. Rheumatol Int. 2013; 33(4): 985-92.

7. Shalchian $\mathbf{S}$, de Wispelaere $\mathbf{F}$. Brucella spondylodiscitis with multiple-level involvement, an unusual clinical presentation. Eur J Neurol. 2007; 14(10): e1-2.

8. Aydin G, Tosun A, Keles I, Ayaşlioglu E, Tosun O, Orkun S. Brucellar spondylodiscitis: a case report. Int J Clin Pract. 2006; 60(11): 1502-5.

9. Brouqui P, Raoult D. Endocarditis due to rare and fastidious bacteria. Clin Microbiol Rev. 2001; 14(1): 177-207.

10. Ibrahim AI, Awad R, Shetty SD, Saad M, Bilal NE. Genitourinary complications of brucellosis. Br J Urol. 1988; 61: 294-8. 